\title{
Inclined Hole Under Different Loading Conditions: A Review of Recent Results
}

\author{
F. Berto ${ }^{\mathrm{a}, 1}$ and Reza H. Afshar ${ }^{\mathrm{b}}$ \\ ${ }^{a}$ Department of Engineering Design and Materials, Norwegian University of Science and Technology \\ (NTNU), Trondheim, Norway \\ ${ }^{\mathrm{b}}$ University of Uppsala, Sweden \\ ${ }^{1}$ berto@gest.unipd.it
}

УДК 539.4

\section{Обзор новейших исследований по оценке концентраторов напряжений типа наклонного отверстия при различных условиях нагружения}

\author{
Ф. Берто ${ }^{\text {, }}$ Реза X. Афшар ${ }^{\sigma}$ \\ ${ }^{\text {a } Н о р в е ж с к и и ̆ ~ у н и в е р с и т е т ~ е с т е с т в е н н ы х ~ и ~ т е х н и ч е с к и х ~ н а у к, ~ Т р о н х е и ̆ м, ~ Н о р в е г и я ~}$ \\ ${ }^{\sigma}$ Уппсальский университет, Уппсала, Швеция
}

Исследовано трехмерное упругое распределение напряжений около острых углов наклонного ромбовидного отверстия в пластине. Проанализирована трехмерная конечноэлементная модель при различных условиях нагружения для изучения интенсивности разрушения при разных модах с учетом толщины пластины. Полученные результаты сравниваются с таковыми, определенными по новейшей теории, которая преобразует трехмерные основные уравнения упругости в систему дифференциальных уравнений, включаюшую бигармоническое и гармоническое уравнения. Последние обеспечивают решение, соответствующее условию в плоскости и вне плоскости надреза, и должны быть одновременно удовлетворены. Получено хорочее соответствие между численньми результатами и теоретическим распределением напряжений.

Ключевые слова: аналитические выражения, конечноэлементный анализ, отверстие, трехмерность.

Introduction. Due to convenience and relative simplicity, solutions of plane theory of elasticity are popular and serve as a basis for many engineering design procedures, standards and failure assessment codes. In terms of numerical costs, two-dimensional models, based on plane stress or plane strain assumptions, are much more computationally efficient, easier to build and verify in comparison with the corresponding three-dimensional counterparts. However, to approach the through-the-thickness effect of real components, requires alternative methods such as three-dimensional theory of elasticity or finite element (FE) method.

The coupling effect was investigated for through-the-thickness cracks in finite thickness plates using analytical and numerical methods [1-3]. In particular, the 3D stress field at sharp notches with arbitrary notch opening angles based on the first order plate theory by [4] is studied in $[5,6]$. The coupled mode in shear loading was called 'the out-of-plane mode, or Mode O', to distinguish it from the conventional Mode III. It was 
also demonstrated that the out-of-plane mode is provoked by the $3 \mathrm{D}$ effects linked to Poisson's ratio of the material and described by the same characteristic equation as the conventional Mode III.

The local interaction between the loading modes for the case of pointed and sharply radiused notches in plates with finite thickness was re-analyzed in [7]. It was demonstrated that the governing equations of three-dimensional elasticity can be reduced to a biharmonic equation and a harmonic equation. The former provides the solution of the corresponding plane notch problem, while the latter gives the anti-plane elasticity problem. Having the two equations simultaneously satisfied in a $3 \mathrm{D}$ problem, justifies the theoretical and mutual interaction between different modes. The main aim of this study is to examine the proposed theory in [7] by investigating the stress fields in the vicinity of the sharp corners of a diamond hole in a plate with finite thickness under tension and twisting loading conditions.

1. Methodology.

1.1. Analysis of the 3D Stress Fields. Recently, a new approach to the analysis of three-dimensional problems has been developed by Lazzarin and Zappalorto [7] who assume the Kane and Mindlin [4] hypothesis for displacement components as given by

$$
u_{x}=u(x, y), \quad u_{y}=v(x, y), \quad u_{z}=b z \times w(x, y),
$$

where $b$ is a constant value. As a result, the normal strains $\varepsilon_{x x}, \varepsilon_{y y}, \varepsilon_{z z}$ as well as $\gamma_{x y}$ are independent of $z$, whereas, the other two shear components, i.e, $\gamma_{y z}$ and $\gamma_{x z}$, depend on $z$. We have

$$
\begin{aligned}
& \varepsilon_{x x}=\frac{\partial u}{\partial x}, \quad \varepsilon_{y y}=\frac{\partial v}{\partial y}, \quad \varepsilon_{z z}=b w, \\
& \gamma_{x y}=\frac{\partial u}{\partial y}+\frac{\partial v}{\partial y}, \quad \gamma_{y z}=b z \frac{\partial w}{\partial y}, \quad \gamma_{x z}=b z \frac{\partial w}{\partial x} .
\end{aligned}
$$

By invoking the stress-strain relationship, also the stress components $\sigma_{x x}, \sigma_{y y}, \tau_{x y}$, and $\sigma_{z z}$ are independent of $z$, whereas the out-of-plane shear stress components depend on $z$, according to the following equations:

$$
\begin{aligned}
\sigma_{z z} & =\frac{E}{(1-2 v)(1+v)}\left[(1-v) \varepsilon_{z z}+v\left(\varepsilon_{x x}+\varepsilon_{y y}\right)\right]= \\
& =\frac{E}{(1-2 v)(1+v)}\left[(1-v) b w+v\left(\frac{\partial u}{\partial x}+\frac{\partial v}{\partial y}\right)\right], \\
\tau_{y z} & =G \gamma_{y z}=G b z \frac{\partial w}{\partial y}, \quad \tau_{x z}=G \gamma_{x z}=G b z \frac{\partial w}{\partial x} .
\end{aligned}
$$

By imposing the equilibrium in $z$ direction, one obtains

$$
\nabla^{2} w=0
$$

where $\nabla^{2}$ denotes the two-dimensional Laplacian operator. Similarly, considering the equilibrium in $x$ and $y$ directions, applying differentiation and by using the Schwarz theorem for partial derivatives, the following equation can be obtained:

$$
\frac{\partial^{2} \sigma_{x x}}{\partial x^{2}}+\frac{\partial^{2} \sigma_{y y}}{\partial y^{2}}+2 \frac{\partial^{2} \tau_{x y}}{\partial y \partial x}=0 .
$$


Due to the fact that the stress components $\sigma_{x x}, \sigma_{y y}, \tau_{x y}$, and $\sigma_{z z}$ do not depend on $z$, Eq. (5) is automatically satisfied by the classic Airy stress function $\phi(x, y)$ :

$$
\sigma_{x x}=\frac{\partial^{2} \phi}{\partial y^{2}}, \quad \sigma_{y y}=\frac{\partial^{2} \phi}{\partial x^{2}}, \quad \tau_{x y}=-\frac{\partial^{2} \phi}{\partial x \partial y} .
$$

Now, by using the generalized Hooke's law for stresses and strains and satisfying the in-plane compatibility equations, one obtains [7]:

$$
\nabla^{4} \phi=v \nabla^{2} \sigma_{z z}=0
$$

Here the equality to zero is guaranteed by the third of the Beltrami-Mitchell equations, considering the fact that the stress components $\sigma_{x x}, \sigma_{y y}, \tau_{x y}$, and $\sigma_{z z}$ do not depend on $z$.

Subsequently, any three-dimensional notch problem can be converted into a biharmonic problem (typical of plane stress or plane strain conditions) and a harmonic problem (typical of out-of-plane shear case), provided that the displacement law according to Kane and Mindlin's Eq. (1) is satisfied. The final equation system is

$$
\left\{\begin{array}{l}
\nabla^{4} \phi=0 \\
\nabla^{2} w=0
\end{array}\right.
$$

where $\phi$ and $w$ are defined implicitly according to Eqs (3) and (6), respectively. Note that, both equations (8) must be satisfied simultaneously.

It is worth mentioning that the solution given in [7] is not valid on the free surfaces of the plate, due to the presence of some edge effects, such as corner point singularities [8-11] that might play an important role on stress intensities.

2. Examples and Applications. In this section, a three dimensional model with an inclined diamond hole in a finite thickness plate under different loading conditions is considered. In order to demonstrate the degree of accuracy of the theory developed in [7], the analytical frame of the theory is explained first and then verified by the $3 \mathrm{D}$ finite element (FE) models under tension and torsion loading conditions respectively.

2.1. The Spatial Diamond Hole Problem. An inclined diamond hole in a plate with finite thickness under tension and torsion is considered. The inclination angle is $22.5^{\circ}$, as shown in Fig. 1. Such an inclination induces local in-plane mixed mode stresses (Mode I + Mode II), which can be solved by using Williams' plane solution for re-entrant corners, according to Eq. (8), where the function $\phi$ is as follows $[7,12]$ :

$$
\begin{aligned}
& \phi=r^{\lambda_{1}+1}\left[A_{s} \cos \left(\left(\lambda_{1}+1\right) \theta\right)+B_{s} \cos \left(\left(1-\lambda_{1}\right) \theta\right)\right]+ \\
& +r^{\lambda_{2}+1}\left[A_{a} \sin \left(\left(\lambda_{2}+1\right) \theta\right)+B_{a} \sin \left(\left(1-\lambda_{2}\right) \theta\right)\right] .
\end{aligned}
$$

Having a fixed value of the through the thickness coordinate, $z$, and using the polar coordinate system at the notch tip, the in-plane stresses vary according to Williams' singularity degrees $1-\lambda_{1}$ and $1-\lambda_{2}$ for Modes I and II, respectively.

In the presence of a sharp V-shaped notch, the stress distributions of symmetric type with respect to the angle bisector (Mode I) are [12-14]: 


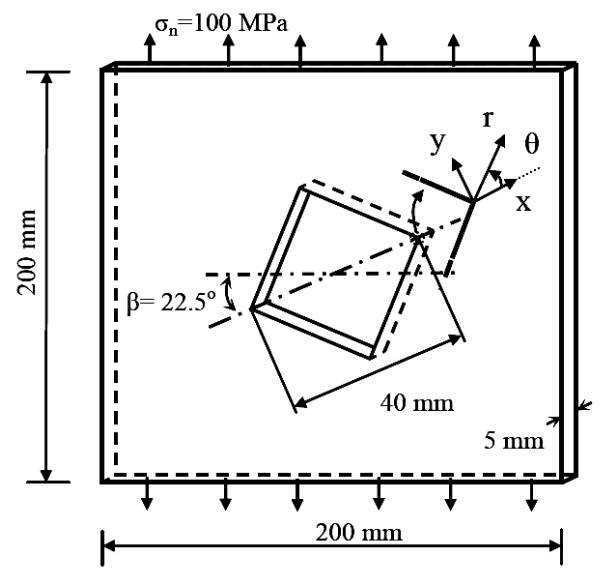

$\mathrm{a}$

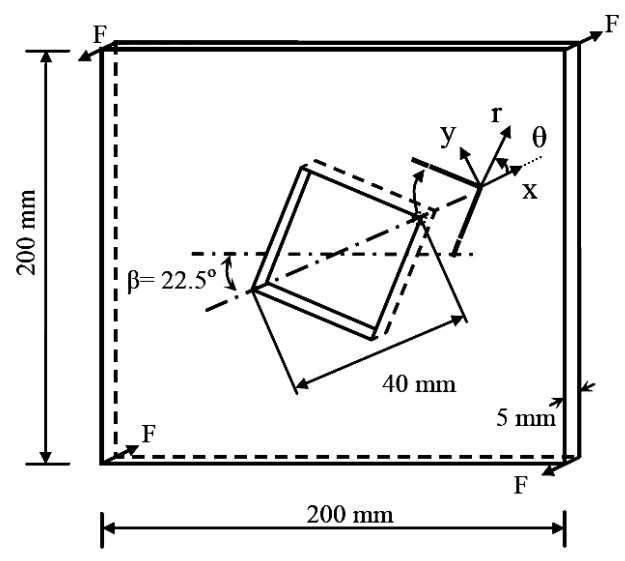

b

Fig. 1. Finite thickness plate weakened by inclined diamond hole under tension (a) and torsion (b).

$$
\begin{gathered}
\left\{\begin{array}{l}
\sigma_{\theta \theta} \\
\sigma_{r r} \\
\tau_{r \theta}
\end{array}\right\}=\frac{1}{\sqrt{2 \pi}} \frac{r^{\lambda_{1}-1} K_{1}}{\left(1+\lambda_{1}\right)+\chi_{1}\left(1-\lambda_{1}\right)} \times \\
\times\left[\left\{\begin{array}{l}
\left(1+\lambda_{1}\right) \cos \left(1-\lambda_{1}\right) \theta \\
\left(3-\lambda_{1}\right) \cos \left(1-\lambda_{1}\right) \theta \\
\left(1-\lambda_{1}\right) \sin \left(1-\lambda_{1}\right) \theta
\end{array}\right\}+\chi_{1}\left(1-\lambda_{1}\right)\left\{\begin{array}{l}
\cos \left(1+\lambda_{1}\right) \theta \\
-\cos \left(1+\lambda_{1}\right) \theta \\
\sin \left(1+\lambda_{1}\right) \theta
\end{array}\right]\right] .
\end{gathered}
$$

The skew-symmetric stress distributions (Mode II) are

$$
\begin{gathered}
\left\{\begin{array}{l}
\sigma_{\theta \theta} \\
\sigma_{r r} \\
\tau_{r \theta}
\end{array}\right\}=\frac{1}{\sqrt{2 \pi}} \frac{r^{\lambda_{2}-1} K_{2}}{\left(1-\lambda_{2}\right)+\chi_{2}\left(1+\lambda_{2}\right)} \times \\
\times\left[\left\{\begin{array}{l}
-\left(1+\lambda_{2}\right) \sin \left(1-\lambda_{2}\right) \theta \\
-\left(3-\lambda_{2}\right) \sin \left(1-\lambda_{2}\right) \theta \\
\left(1-\lambda_{2}\right) \cos \left(1-\lambda_{2}\right) \theta
\end{array}\right\}+\chi_{2}\left(1+\lambda_{2}\right)\left\{\begin{array}{l}
-\sin \left(1+\lambda_{2}\right) \theta \\
\sin \left(1+\lambda_{2}\right) \theta \\
\cos \left(1+\lambda_{2}\right) \theta
\end{array}\right\}\right] .
\end{gathered}
$$

Parameters $K_{1}$ and $K_{2}$ are the notch stress intensity factors (NSIF) related to Mode I and Mode II stress distributions, respectively, $\lambda_{1}$ and $\lambda_{2}$ are Williams' eigenvalues [12] and, finally, $\chi_{1}$ and $\chi_{2}$ are parameters which depend on the opening angle [12-14]. Subsequently, the stress field intensities can be quantified by the corresponding NSIFs [15]:

$$
\left\{\begin{array}{l}
K_{1}(z)=\lim _{r \rightarrow 0} \sqrt{2 \pi} r^{1-\lambda_{1}} \sigma_{\theta \theta}(\theta=0), \\
K_{2}(z)=\lim _{r \rightarrow 0} \sqrt{2 \pi} r^{1-\lambda_{2}} \tau_{r \theta}(\theta=0) .
\end{array}\right.
$$

However, due to the nature of three-dimensional problems, in addition to the in-plane stresses, the out-of-plane shear stress components $\tau_{z r}$ and $\tau_{z \theta}$ can be obtained by using the following $w$ function [16]: 


$$
w=D_{s} r^{\lambda_{3, s}} \cos \left(\lambda_{3, s} \theta\right)+D_{a} r^{\lambda_{3, a}} \sin \left(\lambda_{3, a} \theta\right),
$$

where $\lambda_{3, s}=2 \lambda_{3, a}=\pi / \gamma$, so that only the skew-symmetric part of $w$ contributes to the singular behavior of stress fields [7]. Accordingly, anti-plane Mode III shear stresses near the notch tip can be determined as

$$
\left\{\begin{array}{c}
\tau_{z r}=\frac{K_{3}(z) r^{\lambda_{3, a}-1}}{\sqrt{2 \pi}} \sin \left(\lambda_{3, a} \theta\right), \\
\tau_{z \theta}=\frac{K_{3}(z) r^{\lambda_{3, a}-1}}{\sqrt{2 \pi}} \cos \left(\lambda_{3, a} \theta\right),
\end{array}\right.
$$

and

$$
K_{3}(z)=\lim _{r \rightarrow 0} \sqrt{2 \pi} r^{1-\lambda_{3, a}} \tau_{z \theta}(\theta=0),
$$

where $K_{3}(z)$ is the Mode III NSIF. Equation (15) can be considered as the extension to the out-of-plane mode of Gross and Mandelson's definitions [15] provided for the in-plane modes, see Eqs. (12).

2.2. Tension Loading. In order to validate the theoretical frame developed in [7], a detailed FE analysis on the model shown in Fig. 2 under tension loading is performed. The normal stress $\sigma_{n}=100 \mathrm{MPa}$ is applied on the far end of the plate. The ANSYS package is used to perform the finite element analyses (FEA). Material is assumed as isotropic and linear elastic with the Young modulus $E=206000 \mathrm{MPa}$ and the Poisson's ratio $v=0.3$. The 20-nodes brick element is used. With the aim of obtaining the desired degree of accuracy, a very fine and regular mesh pattern, specially close to the diamond corners is constructed as shown in Fig. 2.

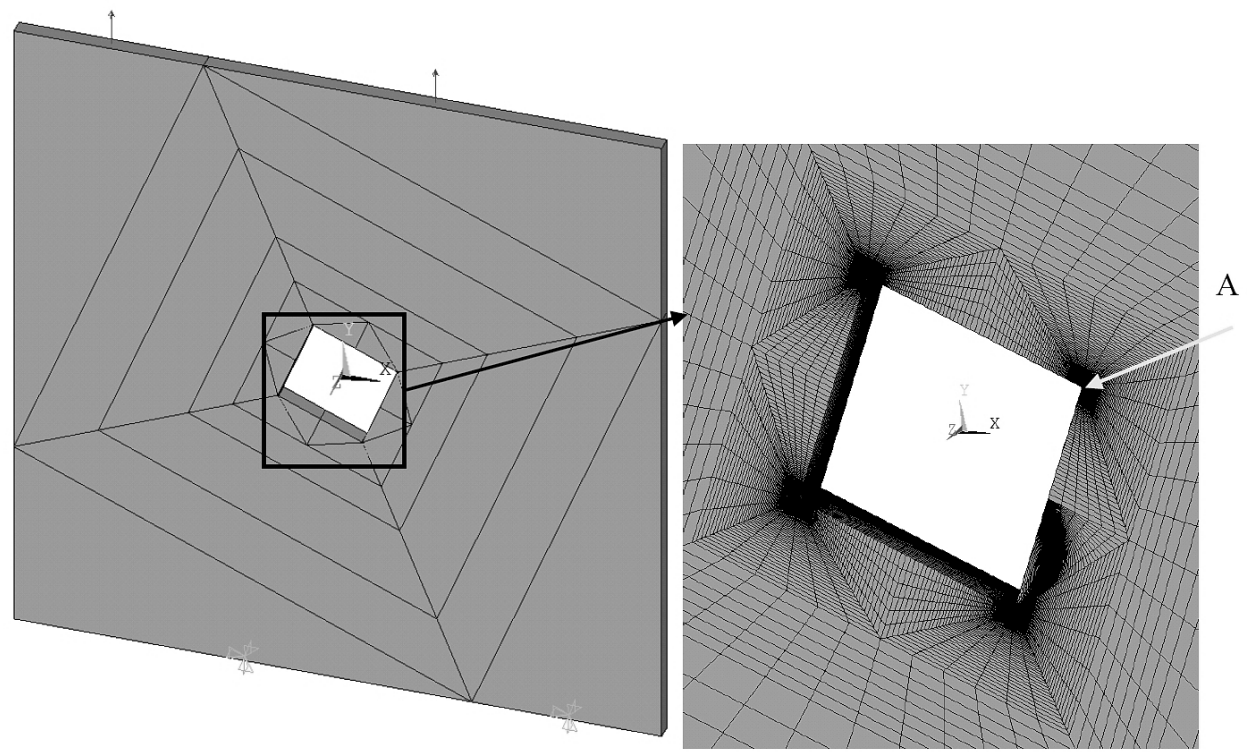

Fig. 2. Mesh pattern used for stress analysis of finite thickness plate weakened by inclined diamond hole under tension.

The variation of three stress components $\sigma_{\theta \theta}, \tau_{r \theta}$, and $\tau_{z \theta}$ along the notch bisector line and close to the notch tip (corner $A$ in Fig. 2) are shown in Fig. 3. All the stresses are 
calculated on the plane $0.5 \mathrm{~mm}$ far from the free surface of the plate. It can be seen from Fig. 3 that, as expected, the value of $\sigma_{\theta \theta}$ is much higher than the other two stresses, showing the dominance of Mode I fracture for the plate under tension.

Figure 4 shows the through the thickness variation of the NSIFs $K_{1}, K_{2}$, and $K_{3}$ in a distance from mid-plane to the free surface of the plate. The notch tip at corner $A$ is selected again for the NSIFs evaluations.

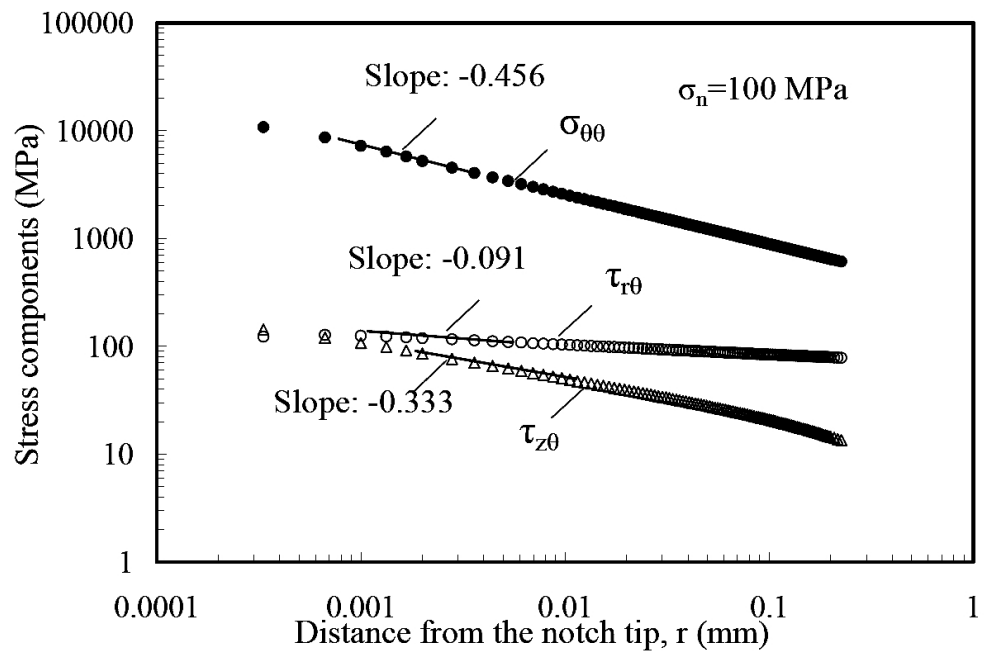

Fig. 3. Stress components $\sigma_{\theta \theta}, \tau_{r \theta}$, and $\tau_{z \theta}$ along the notch bisector line of an inclined diamond hole in a thick plate under tension. Distance from the free surface $z=0.5 \mathrm{~mm}$.

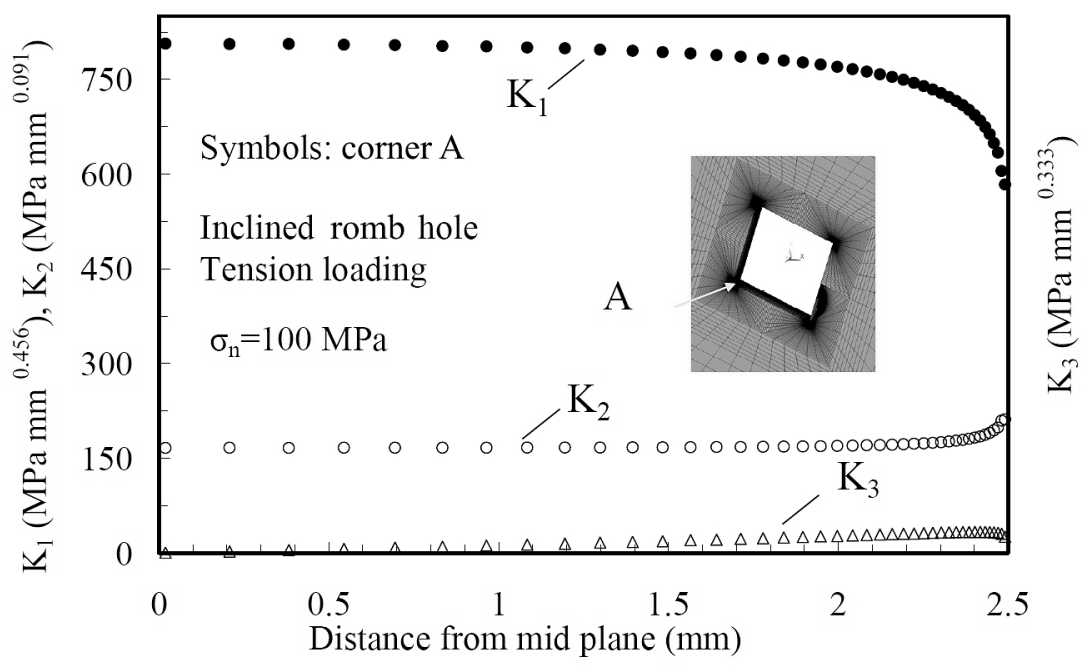

Fig. 4. Plots of NSIFs along the thickness of the plate with inclined diamond hole under tension.

From Fig. 4, it can be observed that the value of $K_{3}$ is relatively lower than the other two NSIFs. The intensity of $K_{3}$ varies from case to case. Here, the main aim was to document the existence of the out-of-plane mode, which can be detected only by means of 3D models. This specific mode is expected to increase as the plate thickness increases [11]. It is evident, the linear change of $K_{3}$ through the thickness of the plate up to the maximum value, which is located in the vicinity of the free surface. In parallel, the 
variability of in-plane NSIFs $\left(K_{1}\right.$ and $\left.K_{2}\right)$ is shown: $K_{2}$ is constant on the major part of the plate thickness, whereas the variation of $K_{1}$ is more distributed through the thickness of the plate.

2.3. Torsion Loading. The plate with inclined diamond hole with the same material properties and element type as of the tension loading is also investigated under torsion loading conditions.

The applied shear stress is set according to the expression $\tau_{n}=3 F / t^{2}$, valid for the narrow rectangular section, which induces a nominal shear stress $\tau_{n}=100 \mathrm{MPa}$ on the gross section of the plate (Fig. 5).

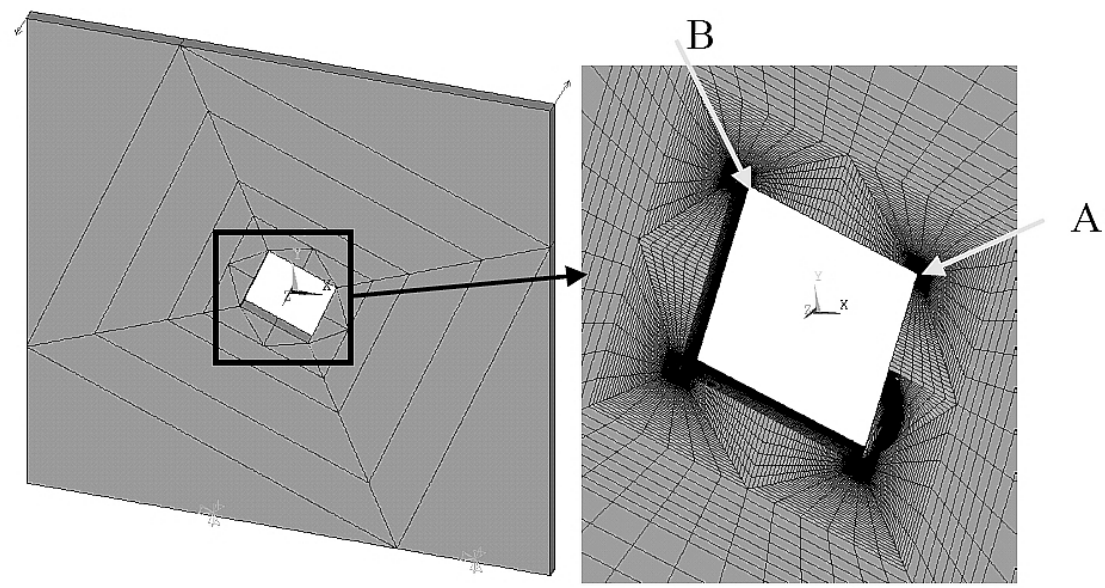

Fig. 5. The mesh pattern used for analysis of finite thickness plate weakened by inclined diamond hole under torsion.

Similar to the tension loading condition, the variation of three stress components $\sigma_{\theta \theta}$, $\tau_{r \theta}$, and $\tau_{z \theta}$ along the notch bisector line and close to the notch tip (corner $A$ ) are shown in Fig. 6. All the stresses are calculated on the plane $0.5 \mathrm{~mm}$ far from the free surface of the plate.

It is worth noting from Fig. 6 that $\sigma_{\theta \theta}$ (corresponding to induced Mode I) is again much higher than the $\tau_{z \theta}$ corresponding to the applied Mode III.

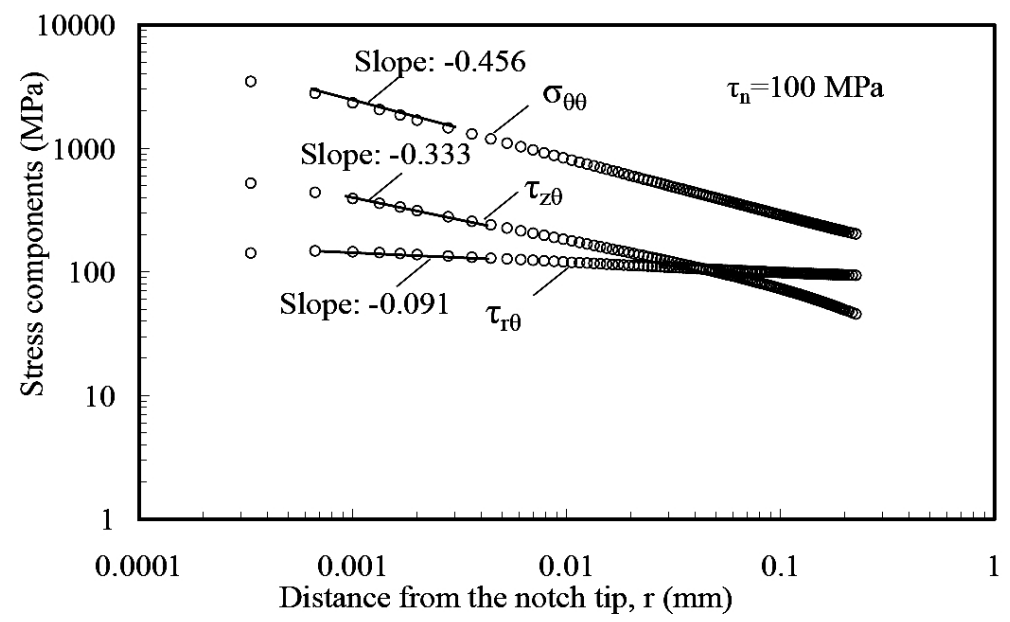

Fig. 6. Stress components $\sigma_{\theta \theta}, \tau_{r \theta}$, and $\tau_{z \theta}$ along the notch bisector line of an inclined diamond hole in a plate under torsion. Distance from the free surface $z=0.5 \mathrm{~mm}$. 
Due to the twisting loading, the stresses at the two corners $A$ and $B$ (Fig. 5) are different. Hence, both corners are considered for NSIFs evaluation through the thickness of the plate, as it is shown in Fig. 7.

Figure 7 shows the linear variation of $K_{1}$ and $K_{2}$ through the thickness of the plate and a parabolic trend of $K_{3}$. It was shown in [17] that the equation system (8) is valid even when the displacement field is no longer according to the Kane-Mindlin hypothesis, i.e., Eq. (1), but is also when given in the following more general form:

$$
u_{x}=f^{\prime}(z) \times u(x, y), \quad u_{y}=f^{\prime}(z) \times v(x, y), \quad u_{z}=f^{\prime}(z) \times w(x, y),
$$

where $f(z)$ can be regarded as a generic polynomial function of order $n$ :

$$
f(z)=a_{0}+a_{1} z+a_{2} z^{2}+\ldots+a_{n} z^{n} .
$$

It is noteworthy that Eq. (17), similar to the equation proposed in [18] for the crack case, automatically satisfies all the six compatibility equations [17].

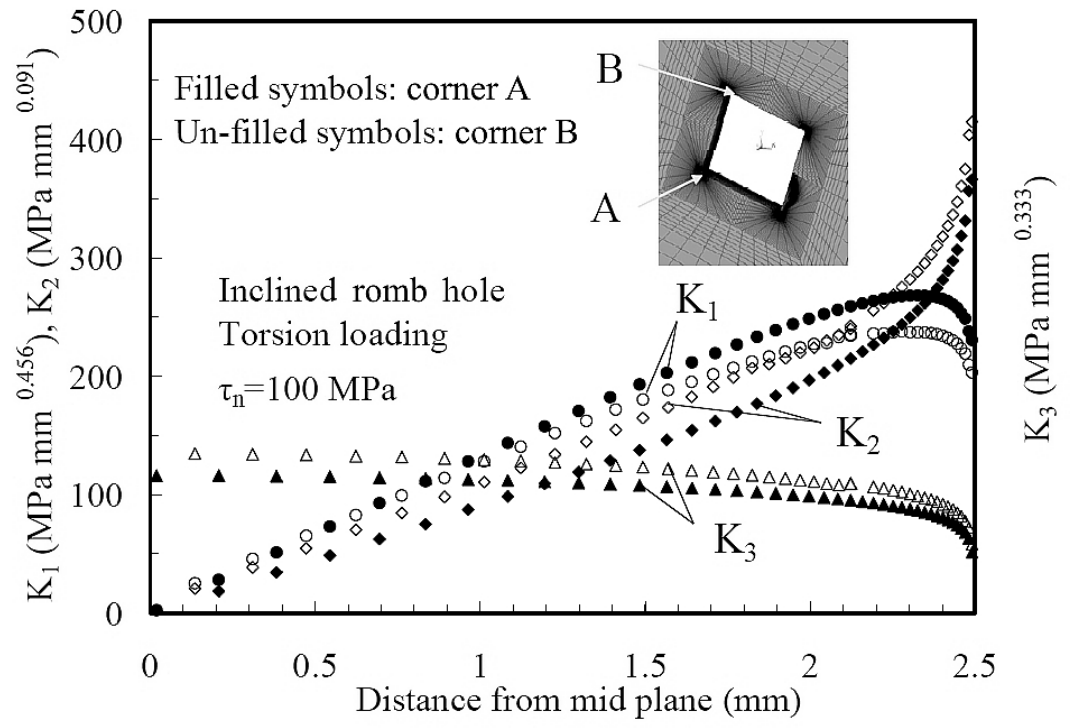

Fig. 7. Plots of NSIFs along the thickness of the plate with inclined diamond hole under torsion.

In addition, apart from very near surface location (i.e., $z>2.25$ from midplane), where some edge effects such as corner point singularity may exist [8-11], on a plane at $z=0.5 \mathrm{~mm}$ from the free surface some differences between the NSIFs values at the two corners $A$ and $B$ can be observed. Considering the corner $A$, the Mode I seems to be the dominant mode of fracture and $K_{2}$ has a relatively lower value (about $25 \%$ lower than $K_{1}$ ) at $z=0.5 \mathrm{~mm}$ from the free surface. On the other hand, for corner $B$, both $K_{1}$ and $K_{2}$ are dominant and have an equal value at the same distance from the free surface. For both corners, Mode III has a negligible effect with a relatively higher value at corner $B$.

Finally, in-plane stress components $\left(\sigma_{\theta \theta}, \sigma_{r r}\right.$, and $\left.\tau_{r \theta}\right)$ as well as anti-plane shear stresses $\left(\tau_{z r}\right.$ and $\left.\tau_{z \theta}\right)$ obtained from FEA on a circular path with radius $r=0.002 \mathrm{~mm}$ centered at the notch tip (corner $A$ ), compared with the theoretical prediction according to Eqs. (10), (11), and (14), are shown in Figs. 8 and 9, respectively. 


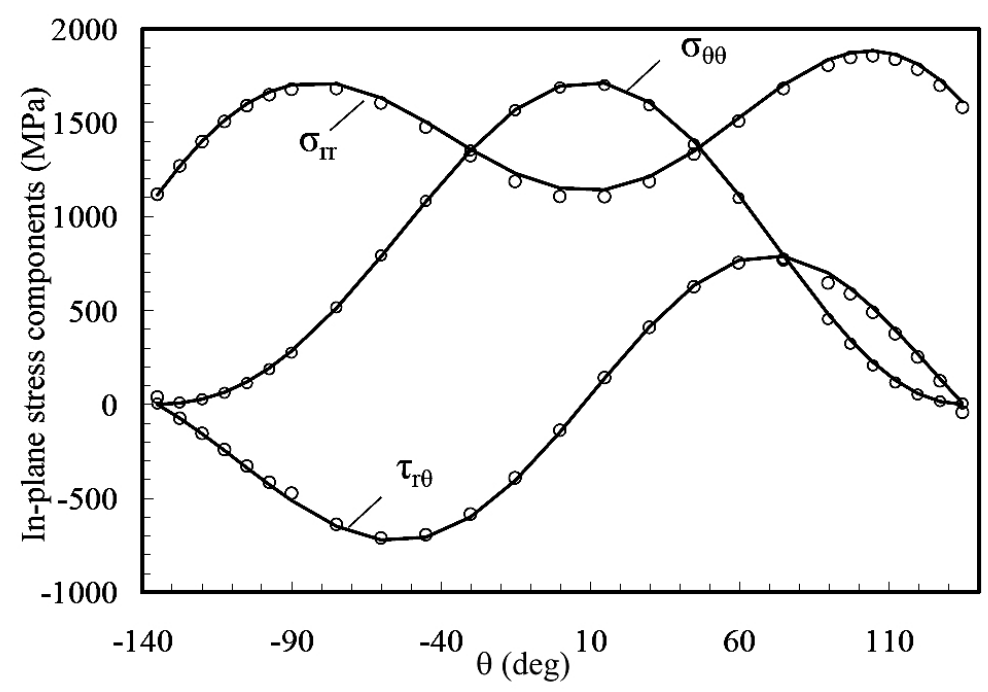

Fig. 8. In-plane stress components $\left(\sigma_{\theta \theta}, \sigma_{r r}\right.$, and $\left.\tau_{r \theta}\right)$ obtained on a circular path with radius $r=0.002 \mathrm{~mm}$ centered at the notch tip (corner $A$ ) and comparison with the theoretical predictions [7]. Inclined diamond hole in a plate under torsion $\left(\tau_{n}=100 \mathrm{MPa}\right)$. Distance from the free surface $z=0.5 \mathrm{~mm}$.

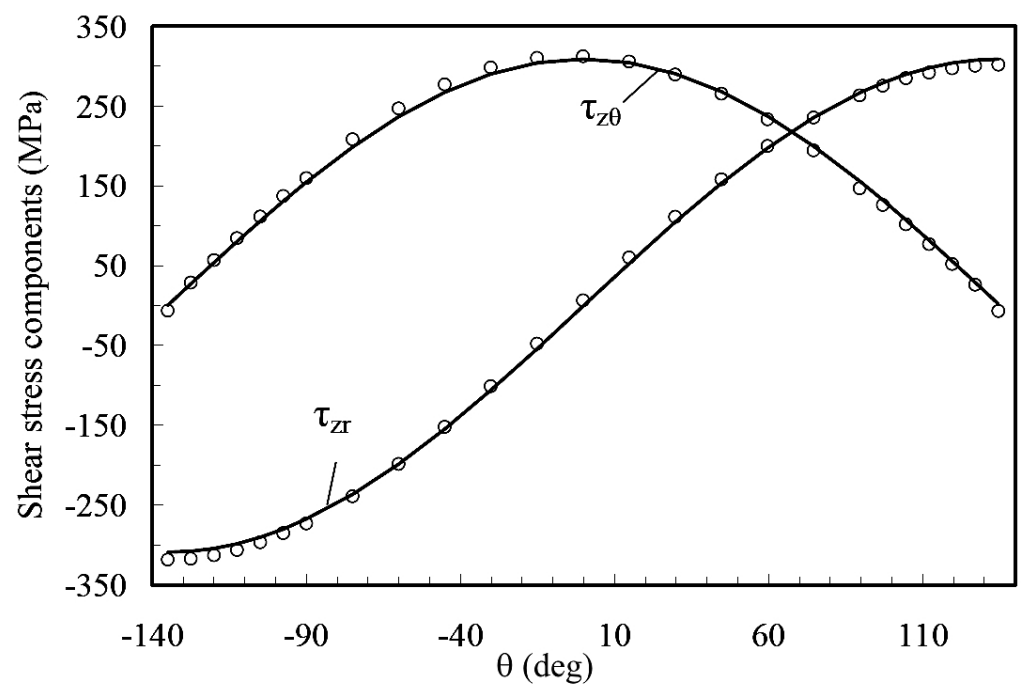

Fig. 9. Anti-plane shear stresses $\left(\tau_{z r}\right.$ and $\left.\tau_{z \theta}\right)$ obtained on a circular path with radius $r=0.002 \mathrm{~mm}$ centered at the notch tip (corner $A$ ) and comparison with the theoretical predictions [7]. Inclined diamond hole in a plate under torsion $\left(\tau_{n}=100 \mathrm{MPa}\right)$. Distance from the free surface $z=0.5 \mathrm{~mm}$.

As it can be seen from Figs. 8 and 9 a very sound agreement is observed between the numerical results and analytical predictions proposed in [7]. A good agreement with the theoretical results was also found for the tension loading conditions.

Conclusions. In this study an attempt is made to examine the proposed theory in [7] by investigating the stress fields in the vicinity of the sharp corners of a diamond hole in a plate with finite thickness under tension and twisting loading conditions. The FE results have confirmed the presence of coupled modes at the V-notch tip, showing a good agreement with the in-plane and out-of-plane theoretical stress distributions. 
Р езюме

Досліджено тривимірний пружний розподіл напружень біля гострих кутів похилого ромбоподібного отвору в пластині. Проаналізовано тривимірну скінченноелементну модель за різних умов навантаження для вивчення інтенсивності руйнування за різних мод 3 урахуванням товщини пластини. Отримані результати порівнюються 3 такими, що визначені за найновішою теорією, яка перетворює тривимірні основні рівняння пружності в систему диференціальних рівнянь, в яку входять бігармонічне і гармонічне рівняння. Останні забезпечують розв'язок, що відповідає умові в площині та поза площиною надрізу, і повинні одночасно задовольнятися. Отримано хорошу відповідність між чисельними результатами і теоретичним розподілом напружень.

1. T. Nakamura and D. M. Parks, "Antisymmetrical 3-D stress field near the crack front of a thin elastic plate," Int. J. Solids Struct., 25, 1411-1426 (1989).

2. Z. H. Jin and R. C. Batra, "A crack at the interface between a Kane-Mindlin plate and a rigid substrate," Eng. Fract. Mech., 57, 343-354 (1997).

3. M. Heyder, K. Kolk, and G. Kuhn, "Numerical and experimental investigations of the influence of corner singularities on 3D fatigue crack propagation," Eng. Fract. Mech., 72, 2095-2105 (2005).

4. T. R. Kane and R. D. Mindlin, "High-frequency extensional vibrations of plates," $J$. Appl. Mech., 23, 277-283 (1956).

5. A. Kotousov, "On stress singularities at angular corners of plates of arbitrary thickness under tension," Int. J. Fracture, 132, 29-36 (2005).

6. A. Kotousov, "Fracture in plates of finite thickness," Int. J. Solids Struct., 44, 8259-8273 (2007).

7. P. Lazzarin and M. Zappalorto, "A three-dimensional stress field solution for pointed and sharply radiused V-notches in plates of finite thickness," Fatigue Fract. Eng. Mater. Struct., 35, 1105-1119 (2012).

8. L. P. Pook, "A finite element analysis of cracked square plates and bars under antiplane loading," Fatigue Fract. Eng. Mater. Struct., 26, 533-541 (2003).

9. L. P. Pook, "Finite element analysis of corner point displacements and stress intensity factors for narrow notches in square sheets and plates," Fatigue Fract. Eng. Mater. Struct., 23, 979-992 (2000).

10. L. P. Pook, “A note on corner point singularities," Int. J. Fatigue, 53, 3-8 (1992).

11. F. Berto, P. Lazzarin, A. Kotousov, and S. Harding, "Out-of-plane singular stress fields in V-notched plates and welded lap joints induced by in-plane shear load conditions," Fatigue Fract. Eng. Mater. Struct., 34, 291-304 (2011).

12. M. L. Williams, "Stress singularities resulting from various boundary conditions in angular corners of plates in extension," J. Appl. Mech., 19, 526-528 (1952).

13. P. Lazzarin and R. Tovo, "A unified approach to the evaluation of linear elastic stress fields in the neighborhood of cracks and notches," Int. J. Fracture, 78, 3-19 (1996).

14. P. Lazzarin and R. Tovo, "A notch intensity factor approach to the stress analysis of welds," Fatigue Fract. Eng. Mater. Struct., 21, 1089-1103 (1998).

15. R. Gross and A. Mendelson, "Plane elastostatic analysis of V-notched plates," Int. J. Fract. Mech., 8, 267-276 (1972).

16. A. Seweryn and K. Molski, "Elastic stress singularities and corresponding generalized stress intensity factors for angular corners under various boundary conditions," Eng. Fract. Mech., 55, 529-556 (1996). 
17. M. Zappalorto and P. Lazzarin, "Three-dimensional elastic stress fields ahead of notches in thick plates under various loading conditions," Eng. Fract. Mech., 108, 75-88 (2013).

18. R. J. Hartranft and G. C. Sih, "An approximate three-dimensional theory of plates with application to crack problems," Int. J. Eng. Sci., 8, 711-729 (1970).

Received 03. 03. 2016 